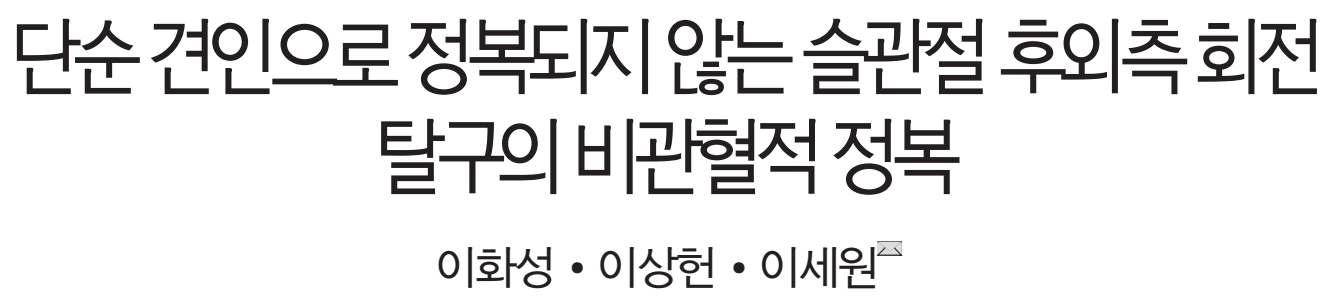

가톨릭대학교 의과대학 여의도성모병원 정형외과학교실

\title{
Closed Reduction of Irreducible Posterolateral Rotatory Knee Dislocation
}

\author{
Hwa-Sung Lee, M.D., Ph.D., Sang-Heon Lee, M.D., and Se-Won Lee, M.D., Ph.D. \\ Department of Orthopedic Surgery, Yeouido St. Mary's Hospital, College of Medicine, The Catholic University of Korea, Seoul, Korea
}

In general, most knee dislocations are reduced easily by simple traction. In rare cases, closed reduction of the knee dislocation is attempted, but ruptured ligaments or muscles are stuck in the joints and cannot be reduced. The cases of this irreducible knee dislocation have sometimes been reported. The authors encountered a case of irreducible knee posterolateral rotational dislocation that was not reduced by simple traction and report it along with a review of the literature. This case provides an opportunity for clinicians to examine the clinical considerations when experiencing an irreducible knee dislocation.

Key words: knee dislocation, therapeutics, orthopedic procedures

슬관절 탈구는 심각하지만 드문 손상으로 모든 정형외과적 손상 의 $0.2 \%$ 미만이다. ${ }^{1)}$ 일반적으로 슬관절 탈구의 대부분은 쉽게 정 복된다. 관절막, 주위 근육, 인대 등이 포착되어 정복되지 않는 경 우는 더욱 드물다. 보조개 징후(dimple sign)가 있는 경우에는 슬 관절 내측 구조물이 포착되어 있음을 의미하고 정복되지 않는 슬 관절 탈구(irreducible knee dislocation)의 특징이다.

저자들은 슬관절 탈구에서 넙다리빗근(sartorius muscle)에 의한 대퇴 내측과 후면 포착이 발생하여 단순 견인으로 정복되지 않는 슬관절 탈구 1 예를 경험하였다. 정복되지 않는 슬관절 탈구 의 증례가 종종 보고되었으나 넙다리빗근에 의한 포착으로 인한 경우가 보고된 경우는 드물다. 저자들은 단순 견인으로 정복되지

\footnotetext{
Received February 19, 2019 Revised May 13, 2019 Accepted May 16, 2019 Correspondence to: Se-Won Lee, M.D., Ph.D.

Department of Orthopedic Surgery, Yeouido St. Mary's Hospital, College of Medicine, The Catholic University of Korea, 10 63-ro, Yeongdeungpo-gu, Seoul 07345, Korea

TEL: +82-2-3779-1068 FAX: +82-2-783-0252 E-mail: ssewon@naver.com ORCID: https://orcid.org/0000-0002-8467-1957
}

않는 슬관절 후외측 회전 탈구를 비관혈적 도수정복으로 정복한 증례 1예를 문헌 고찰과 함께 보고하고자 한다.

\section{증례보고}

53세 남자 환자가 자전거 타던 중 발생한 좌측 슬관절 변형과 통 증을 주소로 본원 응급실에 내원하였다. 수상기전은 자전거 타다 가 좌측 발을 지면에 닿은 채로 방향전환을 하다가 넘어졌다고 하였다. 응급실 내원 후 촬영한 방사선 사진상(수상 2 시간 후 촬 영) 경골이 후외측 방향으로 전위된 슬관절 탈구 소견이 확인되 었다(Fig. 1). 슬부 및 슬부 이하 원위부 하지의 피부색 변화는 없 었으며 도플러 검사에서 슬와동맥, 후경골동맥, 족배동맥 등 하 지 혈행이 이상 없음을 확인하였다. 이점식별검사상 감각이상은 동반되지 않음과 발목관절의 배굴, 저굴이 능동적으로 가능함을 확인한 뒤 견인에 의한 도수정복을 시도하였다. 그러나 환자는 견인과정에서 극심한 통증을 호소하였으며 도수정복을 시도한 후 촬영한 방사선 사진에서 완전히 정복되지 않고 아탈구되어 있 
Hwa-Sung Lee, et al.

는 소견이 확인되었다(Fig. 2).

완전 정복되지 않음을 확인하고 진통제를 투여한 뒤 한 차례 의 추가적인 견인에 의한 도수정복을 시도하였으나 여전히 아탈 구 소견이 방사선 사진에서 확인되었고 환자는 극심한 통증을 호 소하였다. 이러한 과정 중에 환자의 좌측 슬관절 내측부의 피부 색이 까맣게 변하고 있었으며 피부에 주름이 생기는 보조개 징후 가 나타나는 것을 확인하였다(Fig. 3). 족근관절상완지수(ankle brachial index, $\mathrm{ABI}$ )는 1.1로 확인되고(정상범위, 0.9-1.2) 하지 맥박이 잘 촉진되어 혈관 조영 단층화 전산촬영은 진행하지 않았 다. ‘일반적인 견인으로 정복되지 않는 슬관절 아탈구 상태’임을 판단해 더 이상의 견인을 이용한 도수정복을 포기하고 응급으로 자기공명영상(magnetic resonance imaging, MRI)을 촬영하였 다. MRI상 넙다리빗근이 전위된 대퇴 내측과 외측면에 포착되어
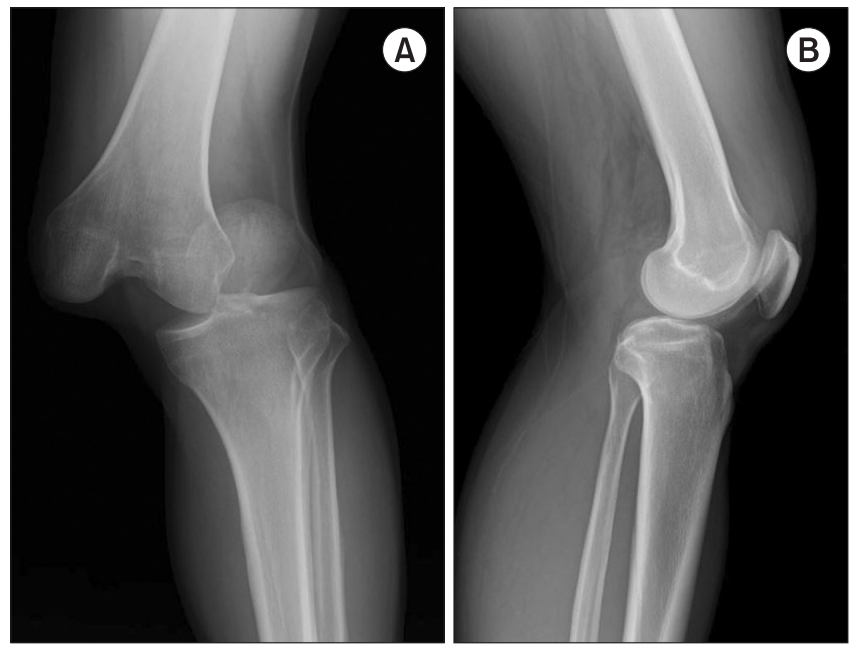

Figure 1. Initial knee anterior-posterior (A) and lateral (B) radiographs.
발생한 단추구멍 효과(buttonhole effect)에 의해 정복되지 않음 을 확인하였다(Fig. 4).

피부색 변화 때문에 더 이상의 시간을 지체하면 안된다고 판단 하였고 또한 환자가 극심한 통증을 호소하였기 때문에 응급 수술 을 계획하였다(수상 8시간째). 수술 전 계획은 전신마취하에 도 수정복을 시도하고 여의치 않을 시 개방적 정복술을 시행할 계획 이었다. 전신마취하에서 넙다리빗근에 의한 단추구멍 효과를 상 쇄하기 위해 (1) 슬관절을 90도이상 굴곡하고, (2) 경골을 내회 전한 상태에서 (3) 경골에 후방 전위를 가했을 때, 클릭음(click sound)과 함께 슬관절의 아탈구가 정복되는 것을 확인하고 보조 개 징후도 해소되는 것을 확인하였다(Fig. 5). 이 증례의 정복과
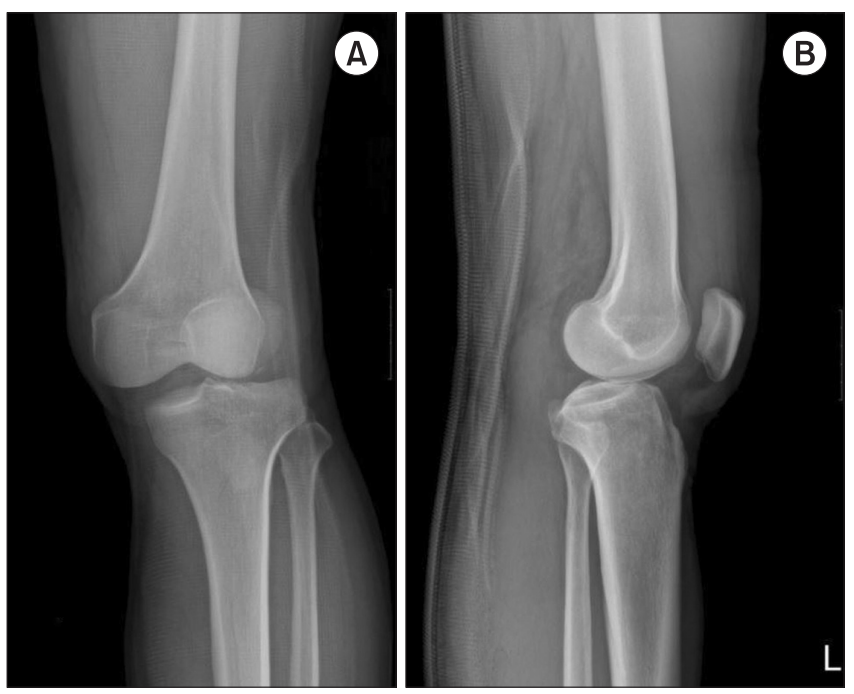

Figure 2. Knee anterior-posterior (A) and lateral (B) radiographs after the initial reduction trial. Subluxation remained.
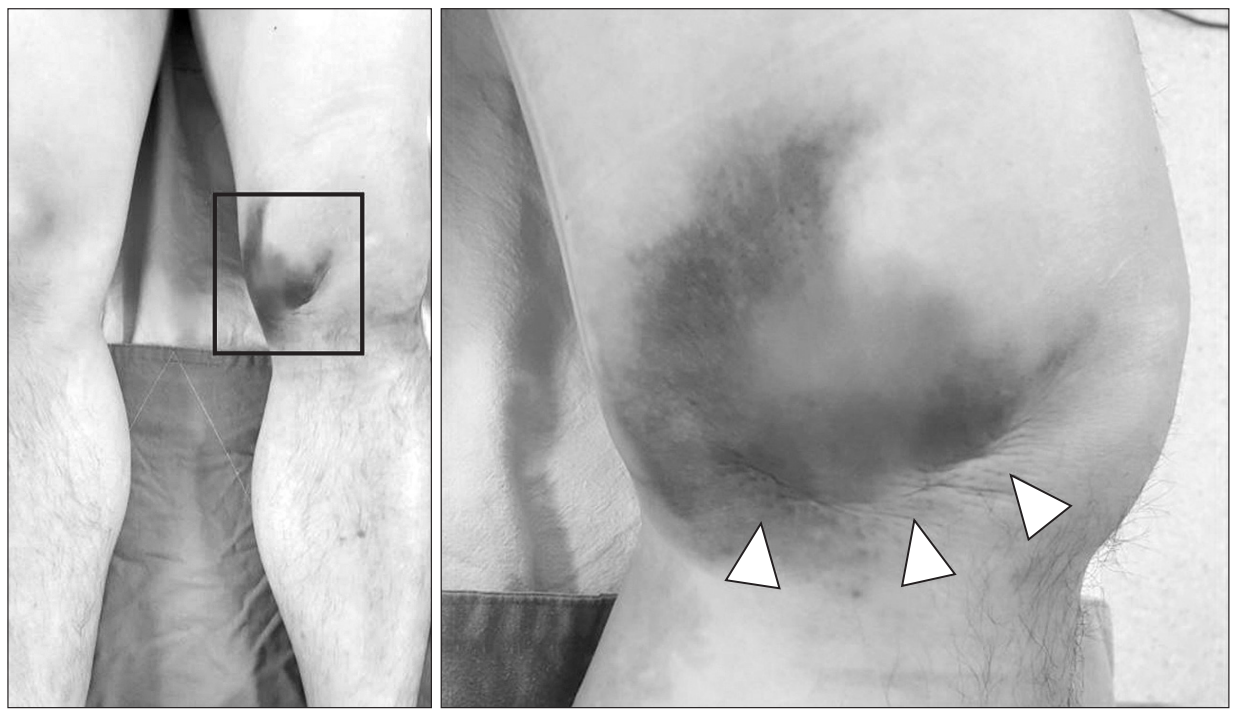

Figure 3. Dimple sign (arrows), also known as the pathognomonic sign of irreducible knee dislocation and skin color change during subluxation of the knee. 

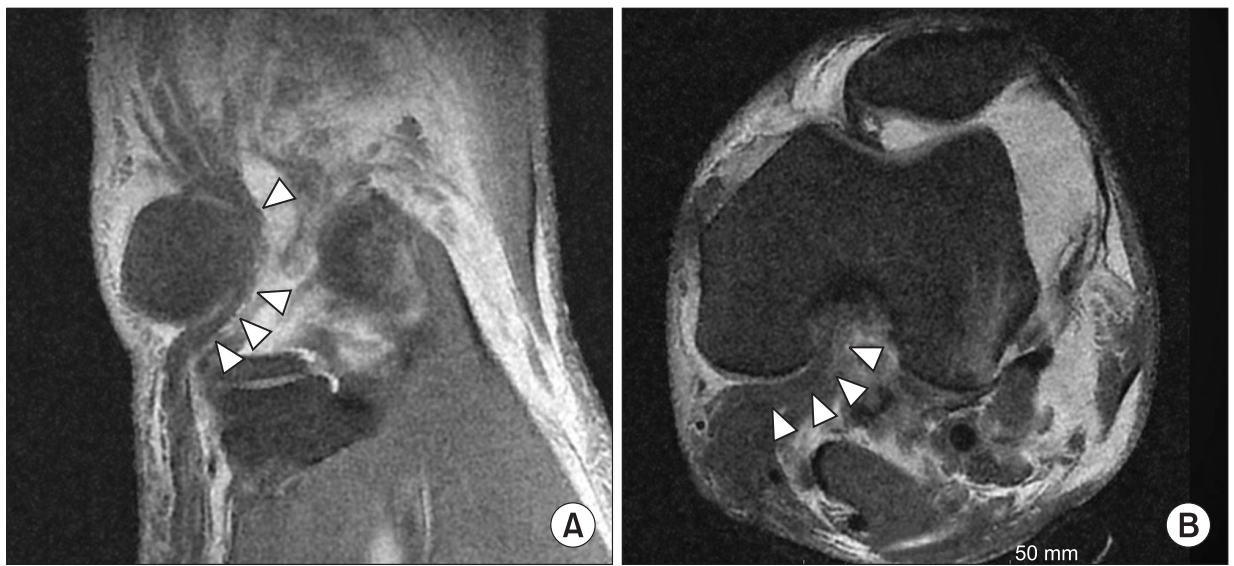

Figure 4. Magnetic resonance imaging of coronal image $(A)$ and axial image $(B)$ taken with remained subluxation of the knee. Sartorius tendon is indicated as arrows. The buttonhole effect is formed.

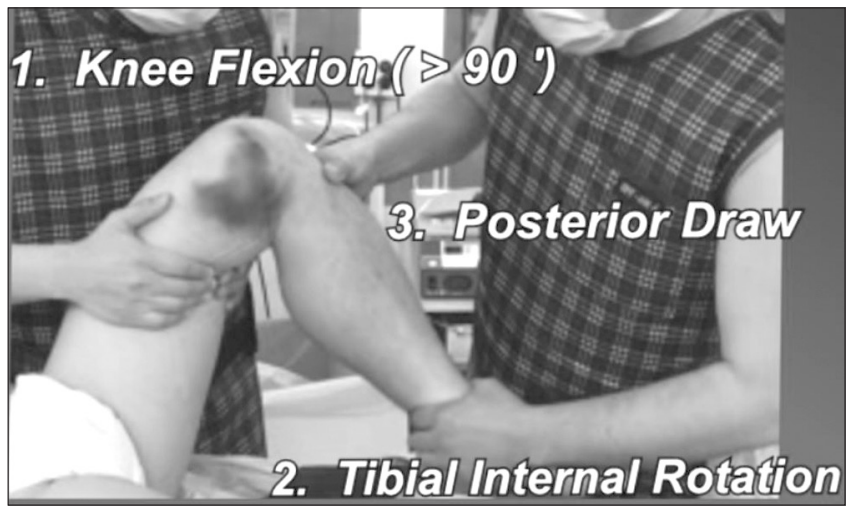

Figure 5. When the knee flexion is more than $90^{\circ}$ with tibial internal rotation, a posterior force is applied to the tibia, and the dimple sign is resolved along with the click sound.

정이 담긴 동영상은 Supplementary에서 확인할 수 있다. 환자 가 술 전에 극심한 통증을 호소했고 슬관절 내측이 일부 까맣게 변하는 소견 때문에 정복된 상태로 외고정을 시행하였다(Fig. 6). 환자는 목발하에 체중부하를 허용하면서 피부상태에 대한 경과 를 관찰했으며 슬관절 내측부의 피부색 변화와 부종은 점차적으 로 호전되었다(Fig. 7). 지연 혈관손상여부를 확인하기 위해 $\mathrm{ABI}$ 의 추시 및 술 후 7일째 혈관조영 컴퓨터단층촬영(computed tomography)을 하였으나 특이 소견은 발견되지 않았다.

MRI상 전방십자인대, 후방십자인대, 내측 지대의 완전 파열 소견 보였고 내측측부인대와 외측측부인대의 대퇴부착부 파열 소견 확인되어 정복 및 외고정 수술 후 3 주째 동종아킬레스건골 이식(allogenic Achilles tendon bone graft)을 이용한 전방십 자인대, 후방십자인대의 동시재건술 및 내측측부인대, 외측측부 인대, 내측지대를 고정봉합(anchor suture)을 이용한 봉합술을 시행하였다(Fig. 8). 재활은 일반적인 후방십자인대 재건술처럼 지연된 재활을 택했다. 수술 직후부터 술 후 2주까지 원기둥 부목 (cylinder splint)을 유지한 채 체중부하 허용 및 목발보행을 허 용하였으며 술 후 2주부터 지속적수동운동(continuous passive
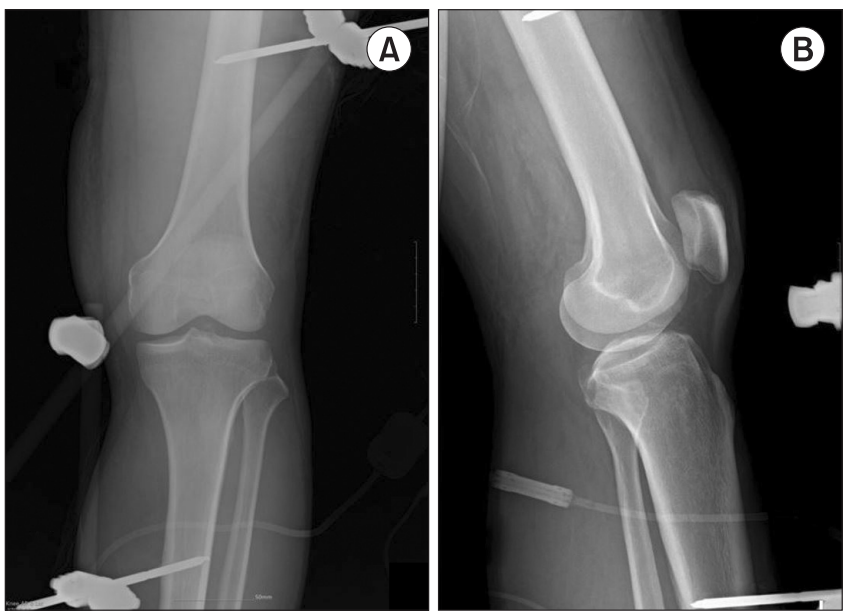

Figure 6. Knee anterior-posterior (A) and lateral (B) radiographs taken after general anesthesia reduction and external fixation, and the knee joint was reduced without subluxation.

motion, $\mathrm{CPM}$ )을 이용한 점진적인 운동범위(range of motion, $\mathrm{ROM}$ ) 내 운동요법을 시행하여 술 후 6주에 90도 굴곡을 획득 하게 하였으며 그 이후 지속적인 운동요법을 통해 술 후 12 주에 거의 완전한 ROM (0-135도)을 획득하였다. 목발보행은 6주간 유지하도록 하였으며 후방십자인대 보조기(posterior cruciate ligament [PCL] brace)는 술 후 3개월째까지 유지하였다. 현재 술 후 10 개월째 외래 추시 중으로 약간의 후방불안정성이 남았 으나(술 후 10개월째 Telos (Telos, Marburg, Germany)상 side to side difference, $3 \mathrm{~mm}$ ) ROM이 유지되고 있고 재탈구는 없 었으며 조깅과 같은 가벼운 운동이 가능한 상태이다.

\section{고 찰}

슬관절 탈구는 관절의 안정성을 유지하는 구조물(전방십자인대, 후방십자인대, 내측측부인대, 외측측부인대, 후외측 안정화 구조 물) 중 일반적으로 전방십자인대, 후방십자인대를 포함한 2 개 이 
Hwa-Sung Lee, etal.
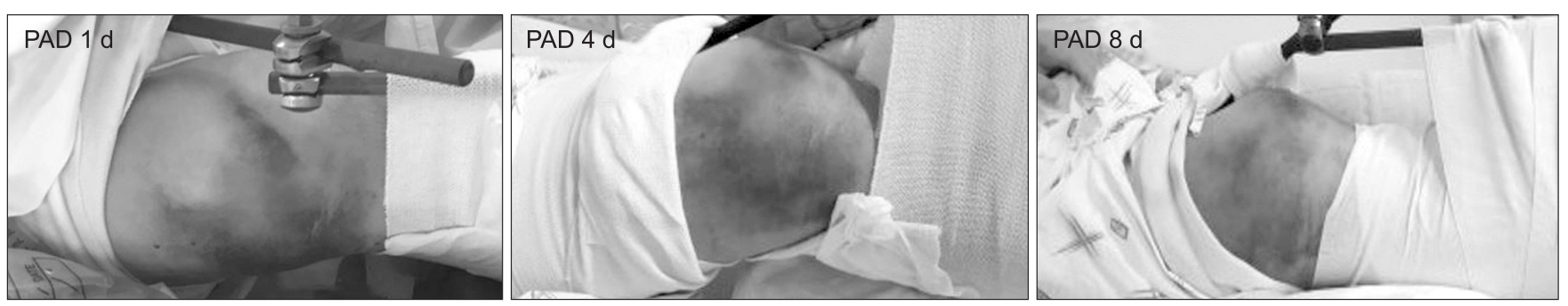

Figure 7. Changes in the skin color in medial side of knee after general anesthesia reduction and external fixation. The color of the medial side of the knee, which has changed considerable, is improving gradually. PAD, post-accident days.

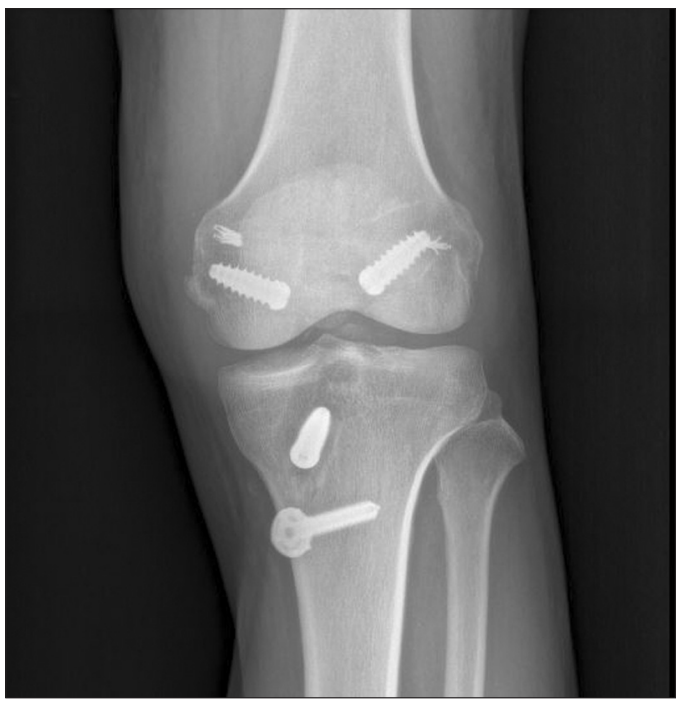

Figure 8. Two weeks after general anesthesia and external fixation, anterior cruciate ligament and posterior cruciate ligament were reconstructed simultaneously with an allogenic Achilles tendon bone graft. And medial collateral ligament, lateral collateral ligament and medial retinaculum were reattached using an anchor suture.

상의 구조물 손상이 동반되었을 때 슬관절 탈구라고 한다. ${ }^{2)}$ 가장 흔한 형태로는 전방, 후방십자인대와 후외측 구조물 또는 후내측 구조물 손상이 동반된 경우이다. 축구 중 태클과 같은 스포츠 손 상, 낙상, 오토바이 운전자 사고, 교통사고 등의 슬관절 부위의 직 접적인 고에너지 손상으로 발생한다. 드물게 저에너지 손상에서 도 슬관절 탈구를 일으킬 수 있다. ${ }^{3)}$

슬관절 탈구의 대부분은 쉽게 정복되기 때문에 병원에 내원하 기 전에 저절로 정복되는 경우도 적지 않다. 슬관절이 탈구된 채 로 내원하는 경우에는 도수정복을 시도하나 인대, 근육, 관절낭 을 포함한 연부조직이 관절에 끼어 정복이 안 되는 경우인, 정복 되지 않는 슬관절 탈구는 매우 드물다. 이 경우 제 때 정복되지 않 는다면 피부 괴사, 혈관 손상, 신경 손상, 구획 증후군 등 여러 가 지 심각한 합병증이 발생하기 때문에 관혈적 정복을 시행해야 하 는 것으로 알려져 있다. ${ }^{4}$

보조개 징후는 정복되지 않는 슬관절 탈구의 질병특유증상으
로 알려져 있으며, 피부가 붙어 있는 관절막이 관절내로 포착되 는 것이 그 주요 이유로 설명되고 있다.4) 관절막 외에도 주위 근 육, 인대 등이 포착되어도 연접한 피부가 견인되기 때문에 보조 개 징후가 나타나게 된다. ${ }^{4-9)}$ 따라서 보조개 징후가 있는 경우에 는 슬관절 내측 구조물이 포착되어 일반적인 도수정복이 불가 능함을 파악해야 한다. ${ }^{8)}$ 찢어진 슬관절 내측 구조물이 내측구획 사이에 포착되는 경우도 있으난) 내측넓은근(vastus medialis muscle)이 포착되는 경우도 문헌상 보고되었고 ${ }^{5.9)}$ 찢어진 내측 반월상 연골판이 포착되는 경우돔문헌상 보고되었다.

정복되지 않는 슬관절 탈구는 슬관절 탈구 중에서 경골의 후 외측 방향 탈구 시 일어난다고 알려져 있다. 일반적으로 고에너 지 손상보다는 저에너지 손상에 의해 생긴다고 알려져 있다. 3.8,10) Tateda 등 ${ }^{10)}$ 은 수상기전은 슬관절이 굴곡된 상태에서 외반(valgus)력과 외회전력이 가해지는 것으로 보고 굴곡, 내반, 내회전 력으로 비관혈적 정복을 성공하였다고 보고했다. 그러나, 수상기 전을 각각의 경우에서 정확히 확인하는 것은 불가능하며, 포착된 구조물에 대한 고려없이 수상기전을 유추하여 비관혈적 정복을 시도하여 성공한 것으로 각각의 사례에서 모두 통용되는 것은 아 닌 것으로 판단된다. 따라서, 포착되는 구조물이 다양할 수 있음 을 인지하고, 정복되지 않는 상태에서는 응급 $\mathrm{MRI}$ 를 촬영해서, 포착되는 구조물에 대한 파악이 더 중요하다고 판단된다.

본 증례에서는 아탈구된 상태에서 MRI를 촬영하여, 넙다리빗 근에 의한 대퇴 내측과 후면 포착이 단추구멍 효과를 일으켜 정 복되지 않는 슬관절 탈구가 발생하는 것을 파악하였다. 포착된 구조물을 확인한 후 그 해부학적 주행을 고려해서 도수정복을 시 행하여 성공하였다.

경골이 후외측 방향으로 전위된 슬관절 탈구가 일반적인 견인 에 의한 도수정복에 의해 정복되지 않는다면 응급 MRI로 포착된 구조물을 확인해 접근해야 하며 만약 본 증례와 같이 넙다리빗근 이 포착된 경우라면 (1) 슬관절을 90도 이상 굴곡, (2) 경골의 내 회전, (3) 경골의 후방전위를 시행하여 비관혈적 도수정복을 시도 할 수 있음을 고려해야 한다. 
Irreducible Knee Dislocation

\section{SUPPLEMENTARY MATERIALS}

Supplementary materials can be found via YouTube. Irreducible knee dislocation. 2018.7.11. https://youtu. be/4RhtpocnNCQ.

\section{CONFLICTS OF INTEREST}

The authors have nothing to disclose.

\section{ORCID}

Hwa-Sung Lee, https://orcid.org/0000-0002-7470-8357

Sang-Heon Lee, https://orcid.org/0000-0002-1327-2166

Se-Won Lee, https://orcid.org/0000-0002-8467-1957

\section{REFERENCES}

1. Kennedy JC. Complete dislocation of the knee joint. J Bone Joint Surg Am. 1963;45:889-904.

2. Robertson A, Nutton RW, Keating JF. Dislocation of the knee. J Bone Joint Surg Br. 2006;88:706-11.

3. Reckling FW, Peltier LF. Acute knee dislocations and their complications. 1969. Clin Orthop Relat Res. 2004;422:13541.

4. Quinlan AG, Sharrard WJ. Postero-lateral dislocation of the knee with capsular interposition. J Bone Joint Surg Br. 1958;40-B:660-3.

5. Bistolfi A, Massazza G, Rosso F, et al. Non-reducible knee dislocation with interposition of the vastus medialis muscle. J Orthop Traumatol. 2011;12:115-8.

6. Durakbaşa MO, Ulkü K, Ermiş MN. Irreducible open posterolateral knee dislocation due to medial meniscus interposition. Acta Orthop Traumatol Turc. 2011;45:382-6.

7. Harb A, Lincoln D, Michaelson J. The MR dimple sign in irreducible posterolateral knee dislocations. Skeletal Radiol. 2009;38:1111-4.

8. Jeevannavar SS, Shettar CM. 'Pucker sign' an indicator of irreducible knee dislocation. BMJ Case Rep. 2013;2013. pii: bcr2013201279.

9. Kilicoglu O, Akman S, Demirhan M, Berkman M. Muscular buttonholing: an unusual cause of irreducible knee dislocation. Arthroscopy. 2001;17:E22.

10. Tateda S, Takahashi A, Aizawa T, Umehara J. Closed reduction of "irreducible" posterolateral knee dislocation - a case report. J Orthop Case Rep. 2016;6:20-3. 


\section{단순견인으로 정복되지 않는 슬관절 후외측 회전 탈구의비관혈적정복 이화성 • 이상헌 • 이세원}

가톨릭대학교 의과대학 여의도성모병원 정형외과학교실

일반적으로 슬관절 탈구의 대부분은 단순 견인에 의하여 쉽게 정복된다. 매우 드물게 슬관절 탈구에서 도수정복을 시도하나 파열 된 인대나 근육이 관절에 끼어 정복되지 않는 경우가 있다. 이러한 정복되지 않는 슬관절 탈구의 증례가 종종 보고되었으나 넙다 리빗근(sartorius muscle)에 의한 포착으로 인한 경우는 문헌상 보고된 바가 없다. 저자들은 단순 견인으로 정복되지 않는 슬관절 후외측 회전 탈구를 비관혈적 도수정복으로 정복한 증례 1 예를 경험하여 문헌 고찰과 함께 보고하고자 한다. 이 증례는 임상의가 도수정복으로 정복되지 않는 슬관절 탈구를 경험할 때 임상적으로 고려해야 할 사항들에 대해 짚어 보는 기회가 될 것으로 생각된다.

색인단어: 슬관절 탈구, 치료 방법, 정형외과적 술기

접수일 2019년 2월 19일 수정일 2019년 5월 13일 게재확정일 2019년 5월 16일

책임저자 이세원

07345 , 서울시 영등포구 63 로 10 , 가톨릭대학교 의과대학 여의도성모병원 정형외과학교실

TEL 02-3779-1068, FAX 02-783-0252, E-mail ssewon@naver.com, ORCID https://orcid.org/0000-0002-8467-1957 